\title{
TEACHING GEOGRAPHY TO CHILDREN WITH LEARNING DIFFICULTIES, IN THE EUROPEAN SCHOOLS
}

\author{
IULIA ŞCHIOPU \\ Brussels European School IV, Brussels, Belgium, e-mail: iulia.schiopu@eeb4.eu
}

(Received: July 2016; in revised form: August 2016)

\begin{abstract}
European Schools offer the opportunity to observe the differences between students and how attention towards the individual is needed. Backed up by a set of frameworks, such as Gestion Mentale, Neuro-linguistic Programming and thinkers such as Paulo Freire, the work of empowering the individual when a challenge is present is exemplified in the context of Geography. What makes a student succeed when the default method is proven challenging. There is no limit as to what methods could be applied as long as they are all guided by the lines of placing the student in a powerful spot: the spot where a challenge becomes a learning opportunity.
\end{abstract}

Keywords: gestion mentale, neuro-linguistic programming, pedagogical dialogue, student-centred methods, individual support

\section{INTRODUCTION}

Putting the student at the centre of the educational process has not always been the guiding rule. The world revolves around the idea that all experience is personalized and customized. Looking at education, it is not abnormal to find value in a personalized look at the students' resources, a personalized method to unleash their potential, giving them the reins, empowering them.

Elements of these new ways of teaching already exist in systems such as the Finnish and the Singapore educational systems. Attention to the 


\section{IULIA ȘCHIOPU}

individual and to small groups, emphasis on debate rather than lecture, personal support as a default rather than as an exception. They are, where applicable, inspirations to systems where average is more the guideline than individual and where the teacher still sits in front of the class instead of being the moderator or the element that encourages critical thinking and creativity.

European Schools (ES) offer even more the opportunity to observe the differences between students and how attention towards the individual is needed. The European Schools are public schools controlled jointly by the governments of the Member States of the European Union (EU). The first ES opened in 1953, in Luxembourg, on the officials' initiative of the European Coal and Steel Community, with the support of the Community's institutions and the Luxembourg Government (www.eursc.eu). It started as an experiment in education where children of different mother tongues and nationalities were educated side by side. This experiment quickly took shape as the six different governments and Ministries of Education of the founders of the European Coal and Steel Community co-operated in matters of curricula, appointment of teachers, inspection and recognition of levels attained.

In 1959, students from ES in Luxembourg had the first European Baccalaureate and the qualification was recognized as fulfilling basic entrance requirements by all the universities of the member states (www.eursc.eu).

Because this educational experiment was a success in that historical context, the European Economic Community and Euratom (created in 1958) were encouraged to press for the establishment of other ES at their various centres. Today, there are fourteen traditional ES in seven different countries (www.eursc.eu).

Based on the recommendation of the European Parliament, the ES have opened up their curricula and the European Baccalaureate since 2005, for national schools. Accredited European Schools are schools that offer a European education that meets the pedagogical requirements laid down for the European Schools, but within the framework of the national school networks of the Member States, and hence outside the legal, administrative and financial framework to which the European Schools are compulsorily subject.

At present, there are twelve Accredited European Schools and other are planned to open ( http://eursc.eu/index.php?|=2).

Educational Principles the ES work with are:

-Basic instruction is given in the official languages of the European Union. This principle allows the primacy of the students' mother tongue (L1) to be safeguarded.

-Consequently, each school comprises several language sections. The curricula and syllabi (except in the case of mother tongue) are the same in all sections.

-The conscience and convictions of individuals are respected. Religious education or education in non-confessional ethics is an integral part of the curriculum. 
- To foster the unity of the school and encourage genuine multicultural education, there is a strong emphasis on the learning, understanding and use of foreign languages. This is developed in a variety of ways. following:

Objectives to be attained by the educational system of the ES are the

- to give students confidence in their own cultural identity - the bedrock for their development as European citizens;

- to provide a broad education of high quality, from nursery level to university-entrance; languages;

- to develop high standards in their mother tongue and in foreign

- to develop mathematical and scientific skills throughout the whole period of schooling;

- to encourage a European and global perspective overall and particularly in the study of human sciences;

- to encourage creativity in music and the plastic arts and an appreciation of all that is best in a common European artistic heritage;

- to develop physical skills and instil in students an appreciation of the need for healthy living through participation in sporting and recreational activities;

- to offer students professional guidance on their choice of subjects and on career/university decisions in the later years of the secondary school;

- to foster tolerance, co-operation, communication and concern for others throughout the school community and beyond;

- to cultivate students' personal, social and academic development and to prepare them for the next stage of education.

- to provide Education for Sustainable Development with a cross curriculum approach, in line with European and international documents.

It can happen that children experience learning difficulties during their schooling either because they could struggle in a particular aspect of a subject, or because they would need to 'catch up' for different reasons or they may have a mild learning difficulty or special educational needs. To be successfully integrated, these children are provided with educational support in different forms and levels. Three types of educational support is available to ensure appropriate help for students experiencing learning difficulties and to allow them develop their potential: general, moderate, and intensive support. Support is flexible and varies as the student develops and changes needs. Detailed description of the support program can be found with the official documents concerning this matter published on the official website of the ES at http://eursc.eu/getfile/1886/2 and http://eursc.eu/getfile/1887/2. 


\section{IULIA ȘCHIOPU}

Within the context of being taught in a multicultural and multilingual environment and the framework of educational support available for children with learning difficulties in the ES, the following problem was raised: how could the use of different learning strategies and frameworks of learning enable students with learning difficulties acquire learning skills, attitudes and knowledge in the context of courses being taught in their second language and not in their mother tongue language?

The objectives of this research were:

1) analysing the impact on learning skills of stundents' own management of their high function cognitive processes (attention, memorization, comprehension, and reflexion);

2) analysing the impact of neurolinguistic programing (NLP) on students' attitudes towards learning and learning skills;

3) analysing the impact on learning of a pedagogical framework where students are subjects in their learning, free of the oppression imposed by a "banking model" of education;

4) analysing the impact of formative assessment strategies on learning skills and on students' attitudes towards learning.

\section{THEORETICAL FRAMEWORK}

Antoine de la Garanderie developed the pedagogical theory called La gestion mentale, a theory that describes precisely the mental gestures consciously present in all learning: attention, memorization, comprehension, reflection, and creative imagination. His theory gives words to express how these cognitive processes happen (De la Garenderie, 2013a, 2013b, 2013c). Through a pedagogical dialogue, teachers can raise the learners' awareness about the strategy of these mental gestures, having as result an increased control over them, thus a bigger autonomy of their own learning.

As a youngster, being himself confronted with learning difficulties because of a partial hearing impairment, Antoine de la Garanderie found that success in learning was more linked to good habits rather than a lack of aptitude. His pedagogical theory was built on the observation of more than a thousand students whom he interviewed during a long period. He was interested in students with high academic performance, in students with learning difficulties, as well as in professional sport men and women. He interviewed both the learners with high academic performance and the professional sport men and women in order to find out their strategies of success used in cognitive processes as attention, memorization, comprehension, reflection, and creative imagination. He did the same thing with students presenting learning difficulties and then he proposed to them to try out or add some new strategies when performing the cognitive processes of attention, memorization, comprehension, reflection, and 
creative imagination. The strategies he proposed were identified in the above group of high achievers.

This principle of identifying successful strategies used by someone and appropriate them can also be found in NLP and is called modelling. Of course, we are all different, so it can be argued that a strategy that is successful for someone is not necessarily successful for someone else. This is a well-appointed argument, and at the same time, all of us use a similar if not the same strategy to open a door, regardless of our differences. There are differences between us and there are also many similarities as well.

Because "La gestion mentale" is based only on psychological and philosophical introspection, psychologists using their assessment instruments looking for measurable performance cannot assess it. In consequence, some cognitive psychologists heavily criticized Antoine de la Garenderie's theory. This is a common point between Antoine de la Garanderie's theory of learning and Sigmund Freud's psychoanalysis theory. Both are based on psychological and philosophical introspection, both are using the dialogue with the client to reach information that cannot be assessed by using standard instruments issued from heuristic models and methods in constant evolution, by definition always imperfect.

The neurolinguistic programming (NLP) is a theory developed by John Grinder, linguistic professor, and Richard Bandler, mathematician, in the 1970 's, in modelling geniuses such as Virginia Satir, an authority of family therapy, Fritz Perls, the founder of gestalt therapy, and Milton Erickson, the most important hypnotherapist. One way of defining NLP is "how to use the mind's own language to consistently achieve our specific and desired outcomes" (Shephard, 2008, p. 1). If we think of dyslexic students, who do not use or have a poor use of internal language when reasoning, the NLP has the potential of a key tool for this constantly expanding group of youngsters. NLP requires an attitude based on curiosity, experimentation and acting as if... (Shephard, 2008, p. 2).

This attitude actually requires students to be active learners and be curious about experimenting, about the results of that experimentation. They should not be afraid of making errors and they should take those negative results as a feedback, giving them the chance to learn and adjust their experimentation in order to get the results they want. Fear is a tool for oppression and, in the classroom context, unfortunately many students experiment this fear because of teachers' reaction to students' actions. In this scenario, teachers become oppressors and students become the oppressed (Freire, 2011). Oppression leads to dehumanization. The teacher being dehumanized by limiting the students' critical capacity to make choices and to transform the reality, "to the extent that man loses his ability to make choices and is subjected to the choices of others, to the extent that his decisions are no longer his own because they result from external prescriptions" (Freire, 2005, p. 4). The students are dehumanized because teachers are limiting their response to the challenges of the environment: "The teacher talks about reality as if it were motionless, static, compartmentalized and predictable. His task is to 'fill' the students 


\section{IULIA ȘCHIOPU}

with the contents of his narration ... narration leads the students to memorize mechanically the narrated content. Worse yet, it turns them into 'containers', into 'receptacles' to be 'filled' by the teacher. The more completely she fills the receptacles, the better a teacher she is" (Freire, 2011 , p. 72). This sums up the "banking" concept of education, in which "the scope of action allowed to students extends only as far as receiving, filing and storing the deposits" (Freire, 2011, p. 72). In this context, knowledge is a gift owned by the teachers upon those they consider to know nothing, the students. In this way, students become objects in their learning, being passive and uninvolved, learning becomes something happening to them and they will not take any responsibility for their results, the oppressor will be the one to blame for. In their turn, students can become oppressors themselves towards younger or weaker students. In the context of education, one can see that this rapport of power could have a negative impact upon learning.

As an alternative to this model of education, where the teacher sits in front of students, all knowledgeable, having all the answers to everything, not allowing any mistakes, denying students' freedom to create, re-create and decide (almost as in an authoritarian regime), Paulo Freire proposed the use of a pedagogical dialogue: "Dialogue is the encounter between men, mediated by the world, in order to name the world. Hence, dialogue cannot occur ... between those who deny others the right to speak their word and those whose right to speak has been denied to them" (Freire, 2011, p. 88). One important condition for the dialogue to exist is to engage in critical thinking, "thinking which perceives reality as process, as transformation, rather than as a static entity" (Freire, 2011, p. 92).

Working with children presenting learning difficulties, a support teacher should be a master in formative assessment. According to Dylan Wiliam, "An assessment functions formatively to the extent that evidence about student achievement is elicited, interpreted, and used by teachers, learners, or their peers to make decisions about the next steps in instruction that are likely to be better than the decision they would have made in the absence of the evidence" (Wiliam, 2011, locations 971-975). In his book, Embedded formative assessment (Wiliam, 2011), he presents five key strategies of formative assessment: 1 . Clarifying, sharing and understanding learning intentions and criteria for success; 2. Engineering classroom activities, discussions and learning tasks that elicit evidence of learning; 3. Providing feedback that moves learning forward; 4. Activating learners as instructional resources for one another; 5. Activating learners as the owners of their own learning. In his latest book, Embedding formative assessment, written together with Siobhán Leahy, they give many examples of practical techniques that serve to the 5 key strategies of formative assessment he has identified.

In the Finnish comprehensive school (9 years of compulsory schooling: primary education of 6 years and secondary 3 years), also called peruskoulu, the aim of special education is "to help and support students by giving them equal opportunities to complete school in accordance with their abilities and alongside their peers" (Sahlberg, 2011, location 1347). 
Students can have access to special education through one of the two pathways: either the student is being included in a regular class and he/she is provided with part-time special education one-to-one or in small groups, or the student is provided with permanent special education in a separate group or class in the student's own school or in a separate institution (Sahlberg, 2011, locations 1351-1354).

In the Finnish system concerning the part time special education, the work of the special education teacher is different at the primary and secondary levels. Reading and writing is being supported extensively during primary school, Finland being a bilingual nation (students learn Finnish and Swedish as mother tongue languages). In 2007, more than $50 \%$ of students enrolled in primary school received support in reading and writing. Almost $20 \%$ of them received support in speech and language, and mathematics. At the secondary level, about $30 \%$ of the students received support in mathematics and foreign languages, much less in reading and writing or speech and language (Takala et al., 2009).

In the 2008-2009 school year, more than one fifth of peruskoulu students were in part time special education, curing minor dysfunctions in speaking, reading, writing or learning difficulties in mathematics or foreign languages. By the end of peruskoulu, up to $50 \%$ of students had been offered special education at some point of their schooling. By the end of the primary school, the number of special needs students in Finland declined and then slightly increased as students moved to subject-based lower secondary school (Sahlberg, 2011, location 1387).

In Finland, the work of a special education teacher seems similar to that of a Special Educational Needs Co-ordinator (SENCo) in UK (Abbott, 2007; Cole, 2005; Layton, 2005; Mackenzie, 2007; Szwed, 2007). SENCos are responsible for assessing, overseeing and co-ordinating all special needs. They also do individual education plans, provide guidance for teachers, they work together with parents and a wide range of assistants and therapists.

In a study conducted by Takala et al. (2009) on the work of special education teachers in mainstream education in Finland, the authors identified three elements of the special education teachers' work: teaching (direct work), consulting and background work (indirect work) (p. 165).

The direct work (that is, teaching students) could be grouped into three main categories (Takala et al., 2009, p. 165): individual teaching, teaching a small group and teaching children in co-operation with the class or subject teacher in a large class. Most of the teaching was undertaken in small groups of children (between two and 10 students, the average being four students in a group), and very little time was spent in co-operational settings.

The indirect work was divided into eight different categories in the questionnaire, namely (Takala et al., 2009, p. 165): (1) consulting with the class teacher, (2) consulting with the subject teacher, (3) co-operation with parents, (4) co-operation with the students' welfare team, (5) assessment, (6) finding/buying/ making materials, (7) planning, and (8) doing 


\section{IULIA ȘCHIOPU}

something else (or 'other'). Most of the indirect work consisted of planning, material design, and assessment. The 'other' consisted mainly of three activities: (1) consulting with a partner, such as the head of the school, the school psychologist or staff at day-care centres or at secondary schools, (2) writing a variety of documents, such as Individual Educational Plans (IEPS), and (3) participating in official school meetings and projects. Participation in various training events and courses was also mentioned.

In a different study conducted in US by Cummings et al. (2008), they identified a list of key activities for special educators in the context of the Response to Intervention approach, approach which appeared due to the intersection of The Individuals With Disabilities Education Improvement Act legislation of 2004 (IDEA, 2004) and The No Child Left Behind Act legislation of 2001 (NCLB). Special education teachers need to support efforts to implement a problem-solving framework premised on four basic questions (Cummings et al., 2008, p. 29): 1. What is the student's problem and why is it happening? 2. What is the best instructional plan for the student given the analysis of the concern? 3. How can the plan be implemented as it was conceived and data collected for analysis of performance? 4. Are the desired results being achieved as expected or do changes need to be made? The special education teacher should be able to evaluate a target student's concern in comparison to an accepted standard of success. Assist and/or train the school's universal screening team to administer formative assessments with fidelity. Once a student's problems are defined and accurately analysed, special educators help other educators with consideration of scientifically based and researched instructional strategies to be used. By linking reliable instructional strategies that match the analysed need of a student, special education teachers help establish meaningful goals for student attainment and meaningful methods of monitoring progress towards those goals. After a well-conceived plan is developed, the special education teacher provides modelling, support, and feedback on the implementation of the intervention. The knowledge of what and how to teach hard-to-reach students is an important feature of special education teachers. Finally, special education teachers become involved in ongoing, formative assessments, as well as in summative evaluation.

\section{MATERIAL AND METHOD}

This study involved two students of secondary levels, one of 14 years of age and the second being 15 years old. Both boys, the younger one being in S4 (the equivalent of the first year of high school in Romania) and the older one being in S5 (the equivalent of the second year of high school in Romania). Both from the francophone section, with French as their mother tongue. The support lessons referred to their geography course, course held in their second language of study, English. 
Both students have a medical or psychological diagnose. The younger one has a sever dyslexia and the older one was diagnosed with executive function disorder. The older student received support twice a week, while the younger one once a week. The last school year, the younger student passed at limit the human science course (course including history and geography taught in English) and the older student failed his geography course.

As Paulo Freire said, there is a difference between integration and adaptation: "Integration results from the capacity to adapt oneself to reality plus the critical capacity to make choices and to transform that reality. If man is incapable of changing reality, he adjusts himself instead. Adaptation is behaviour characteristic of the animal sphere ... adaptation representing at most a weak form of self-defence." (Freire, 2005, p. 4). The banking model of education regards students as adaptable, more they work at storing and depositing information, the less they develop "the critical consciousness. It attempts to control thinking and action. For the naive thinker, the important thing is accommodation to this normalized 'today'. For the critic the important thing is the continuing transformation of reality." (Freire, 2011, p. 92).

With this in mind, the geography support lessons were not designed to "deposit" information in students' brain. Information gave in the geography course was used to develop critical thinking, learning strategies, and increase awareness about phenomena in relation to geography.

First, the accuracy of the students' ability to mentally represent information was checked (the equivalent of what is called in psychology the cognitive process of representation). If students are not able to correctly fulfil this mental gesture (called by Antoine de la Garanderie I'évocation), no learning can happen. If this is the case, there are activities that can be done, using new information to the student, information with geographical background, in order to elicit his strategy of mental representation of information. Then, through the pedagogical dialogue, asking questions rather than giving answers, the student will be helped to become aware of his strategy and the gaps in it. This increase in awareness regarding student's own strategies is sometimes called meta-cognition (De la Garenderie, 2013a, p. 672).

Then, it is being checked that the mental gesture of attention happens correctly. The number of students who have no idea what it means to be attentive could impress one. Luckily, Antoine de la Garanderie gave a specific vocabulary to be used when describing this gesture to students. Again, if this mental gesture is not being done correctly a very poor learning will happen. The definition and meaning of attention is being elicited from students and if they cannot give it, it is given and explained to them, what is being expected from them to do when they should pay attention to something.

If there are no problems with the mental representation of information and with the attention, the student is being asked to have a glance over the lesson for 1 minute in order to find the gist of the lesson. He is encouraged to use the pictures he has on the page, the titles, subtitles and any words written in special characters (i.e. like bold or italics). All 


\section{IULIA ȘCHIOPU}

these represent keywords that will help with the comprehension of the text, will be used to design mind-maps and they will represent the skeleton when writing and developing paragraphs about that subject. After identifying the main idea of the text, the student will write one or two sentences that reflect the main idea. After, the student is being asked to write down all the information he is being expected to discover in relation to the main idea. Then, he was asked to imagine what skills are expected from him to apply or develop in relation to the information he had anticipated to be discovered right before (an exercise of anticipating the learning intentions of the lesson). Anticipation is a very important skill to be developed in students and, unfortunately, it is not as highly regarded, as it should be.

The next step is reading the text and its comprehension. Antoine de la Garanderie said that some people need to comprehend something in order to memorize, while others need to memorize first the information to have access to comprehension. Because these students are being taught in their second language their geography course, it was found of high importance to make sure they understand the vocabulary and that they are able to comprehend the message of the text. In order to comprehend, first one has to be able to engage attention correctly, then to make the selection of clue words or key words in a paragraph correctly. If they stop here, then they will have only the impression of comprehension. The next step in comprehension is to make connections with the information one already has stored in their memory about the subject and then to reformulate the idea with their own words. The comprehension can be affected if students do not fulfil the attention gesture correctly, or if they stop at the key word selection, or if they are not able to make connections with the already known information about the subject (i.e. they do not integrate the information) or if they do not rephrase the idea using their own words. One or more factors cumulated together can affect comprehension.

One student involved in this study was diagnosed with executive function disorder. Actually, for him, making connection was quite challenging. Students can be helped and taught how to link new information to what they already know. Making analogies forces the pupil to think of similarities and differences between the new information and the stock of information they already have. Venn diagrams are very useful in situations like these. If a student finds it difficult to look for similarities between two bits of information he/she can be helped by using questions chunking up (vertically) like "What is this an example of?" In the context of a geography lesson with the older student, this question was used in order for him to realize the similarities between earthquakes and volcanoes. The question chunking up was Teacher (T): "What is the earthquake an example of?" Answer, Student (S): "The earthquake is an example of the movement of tectonic plates". It was elicited the big category, more abstract, more conceptual. Then the teacher needed to ask a question chunking horizontally in order to obtain a second example from the same big category, ( $\mathrm{T})$ : "What are other examples of tectonic plates' movement?" (S): "Volcanoes". (T): "So how are volcanoes and the earthquakes similar?" (S): "They are both examples of tectonic plates' movement". 
Questions given by Dylan Wiliam under the name of question shell can be also used to help students see the similarities and differences between two or more objects, ideas, pieces of information, etc. Here are given some examples of these questions: "How are ... and ... different/similar?"; "What is the difference between ... and ...?"; "Why is ... an example of ...?" "Compare ... and ... in terms of ...?"(Wiliam, 2015, locations 2163-2186).

Assisting students in identifying the similarities between two or more objects helps them in making categories, thus in generalizing. Learning cannot take place or it takes place with a lot of struggle if one is not able to generalize. Let us compare and contrast a person with autism and a person without autism. People having autism find it difficult to recognize and place in the same category an image of a dog that is different from their stored image of the dog. They will have to memorize all the images they come across of dogs and if someone presents a new photo of a dog that those having autism do not already possess in their memory, they will not recognize the image of that one dog. This means that their capacity of generalizing in order to make categories is being affected (De Clercq, 2006). Students struggling to generalize, outside the condition of autism, will have difficulties in learning rules. They will learn the exceptions and not the general rule. These students are too much into details and they need to be taught to acknowledge the global point of view. These students could easily get into conflicts because they will ignore the intention behind someone's actions (which is a much more global point of view) and they will be stuck in the specifics of the action that they do not approve of.

On the contrary, if students struggle with seeing the differences between two actions/ideas/information they will be able to learn the rule, but they will have difficulties in learning the exceptions. These pupils overgeneralize everything and will struggle to see the difference between two bits of information. Asked, "how are the volcanoes and earthquakes different", they will answer "they are the same".

Of course, these two examples are extreme. Most students do not find themselves in these extremes. However, they could have one of the two tendencies and this will have an impact upon their learning. This is why stimulating both types of analogies, similarities and differences, is important in order to have a balance in learning.

Another way of altering the comprehension is by not being able to say the information using your own words. One of the reasons this might happen is because the students do not own yet the required vocabulary. Antoine de la Garanderie describes accurately in his book Pédagogie des moyens d'apprendre the gesture of memorization and what someone needs to do to make sure they will explore at maximum their potential for memorizing.

To increase students' ability to rephrase an idea using their own words, a question proposed by Dylan Wiliam (2015, locations 2163-2186) can be used: "How would you explain ... to a student in the ... grade?" As an example: "How would you explain tectonic plates' movement to a student in the first year of secondary?" 


\section{IULIA ȘCHIOPU}

In relation to the comprehension of a task/question, students were presented with a framework that enabled them to categorize the questions in one or more of the four groups of questions:

1. cause $\rightarrow$ action $\rightarrow$ consequence; under the word cause, one can also place words like initial state, start, starting point; under the word action, one can also place words like middle state, process, event, behaviour, and, under the word consequence, one can also place words like final state, result, effect, conclusion, the end.

2. high reasoning vs. Iow reasoning task/questions. High reasoning questions ask the student to give his/her point of view in relation to an event, a piece of information, an action, a subject, etc. This type of questions also can ask the student to anticipate results or anything in relation to the word consequence or any other word that can be found under the word consequence, from the first type of question. In doing so, the student will have to support his or her arguments on facts and clear proof. Many youngsters, even at the age of 16, still make confusions between facts and opinions. The answer to this type of question is not written in the text, it is not obvious. In the case of the low reasoning questions, the answer can be found written in the text or it is clearly stated in the video or the material the student is working with.

3. comparing and contrasting. Here the student has to identify and expose the similarities or the differences or both, between two or more causes, actions, consequences, concepts, or between any two or more given elements.

4. recalling tasks/questions, where students must just recall an information and give the answer.

5. segmentation task/question, where students first have to recall the necessary information and then to use it to give the answer, to put the recalled information in the right order and compose the answer.

Geography is a highly appropriate course to stimulate students with all these types of tasks/questions. It has many facts (for example, from Physical Geography), as well as the possibility to make anticipation (for example, the economic geography involving migration, natural disasters, etc.). The cause - consequence relation can be worked in depth using phenomena from different fields of geography.

One task/question can be placed in one or more of these five presented categories.

At the end of the lesson, students are asked to check and see if the information and skills they have anticipated at the beginning of the lesson relate to what they have found while reading the lesson. If yes, they are congratulated. If no, they are asked to redefine and make more accurate statements about the information they have discovered and the skills they are to apply or develop through that specific lesson.

As homework, students will have to imagine a future test, play the role of the teacher and design the test based on the information and skills 
acquired during the lesson. This strategy is of high importance for both students and teacher. For students, this exercise is intimately related with the gesture of memorization (De la Garenderie, 2013c, pp. 335-339). For teachers, this method represents a valuable tool for formative assessment. The type of questions a student creates gives the teacher evidence of where he/she is in the learning process (Wiliam, 2015, location 2137). As a result, the support teachers can adapt their teaching to facilitate students' learning.

\section{RESULTS}

The feedback coming from students, parents and teachers involved in this study was a positive one. The end of the year mark increased with one point for the younger student and 2 points for the older student. Their geography teachers made positive comments about the confidence and the level of participation of both students during the geography lessons. The questions asked especially by the older student were more complex and belonging more to the high reasoning category of questions or demanding the teacher to make analogies in relation to other subjects they have studied during geography lessons. During geography tests, if a question/task was referring to a cause $\rightarrow$ consequence situation, the older student was more successful in identifying if the question relates to the cause of an event, phenomena or its consequence (geography tests from the previous school year were compared with the geography tests from the current year; there were also compared geography tests from the first half of the current school year with tests held in the second half of the current school year).

In the case of the older student, an increase of two points in the end of the year mark was observed in his history course. The comments his history teacher made were similar to the comments made by his geography teacher in the end of the school year. In all rightness, this student was accompanied in making the transfer of learned skills during the support lesson for geography to other similar subjects. In this transfer, the support teacher assisted him during the support lessons. Unfortunately, teachers are not assisting many students who develop skills in one area or one specific context to make the transfer of those skills in a different context. Antoine de la Garanderie has insisted on the fact that all children are being successful in one or more areas. These areas can be related to school or not, they could refer to activities like sports, arts, cooking, etc. He has emphasized that fact that if a child has the skills and strategies to be successful in a specific context, what the teacher should do is to accompany that child in transferring those skills and strategies first in a very similar context and then to less similar contexts. Dylan Wiliams says "as teachers, we are not interested in our students' ability to do what we have taught them to do. We are only interested in their ability to apply their newly acquired knowledge to a similar but different context" (Wiliam, 2011, location 1280). 


\section{IULIA ȘCHIOPU}

During the end of the school year special educational needs council, parents made very positive comments upon the evolution their children had registered in courses like geography and history, as well as upon the evolution with their second language (English).

\section{DISCUSSION}

All theories that represent the framework of this study have one point in common: all of them put students in the centre of the learning process. But this was a slow process (for the case of Romania, see a recent research paper by Dulamă and Ilovan, 2015). Students become responsible of their learning, they are subjects doing the learning (Dulamă and Ilovan, 2006, 2009). The support teacher is responsible for the creation and maintenance of an environment that stimulates and enables the students' innate attitudes and abilities to develop and grow into new, different or more performed skills, attitudes, and knowledge. This environment contains all the resources a special education needs teacher should possess, like a solid knowledge in the field of education, special education and psychology, good interaction skills and high ability to make and keep the rapport with students and all the actors involved in the education of youngsters.

If every actor involved in the education of a child seeks results instead of excuses, is being responsible for their results, integrates the results they have into their reality and re-acts to make them even better, then all actors will be subjects in the educational process.

Establishing goals is of high importance to the education process. Antoine de la Garanderie has said that every instruction given to students should represent a "projet" (project), ending in a goal. There is an important difference between the two following statements: "Read this paragraph" and "Read this paragraph in order to be able to reproduce it from your head" or "Read this paragraph to be able to answer some questions I'll ask you about the content of the paragraph". The first statement has no project, there is no goal whatsoever in reading that paragraph. When giving a task like the first statement, students will not have a clear point in reading the text; they will have no goal to follow. A good analogy will be that of a man in a boat, lost in the middle of the ocean. Teachers have to guide the students' mindset to a clear end.

A teacher's mindset is projected on her/his student and the teacher's perception of that student is nothing else than her/his own projection. A teacher who allows students to make errors and sees this as a learning opportunity (because there is no failure, only feedback), a teacher who accepts that everyone has a unique model of the world which can be different from her/his own, a teacher who believes that every student does the best he/she can with the available resources, a teacher who understands that the meaning of communication is the response she/he gets and sees the resistance in students as a sign of a lack of rapport, 
shows a high level of flexibility. The person with the highest behaviour flexibility has the greatest influence on others. If the teacher integrates the learning about her/his students and adapts the teaching to better respond to the student's needs, this will be closely followed by success.

This study presents some limits. First, it was made only on two subjects. Secondly, it is true that we have clear evidence of an increase in the two students' knowledge and skills (improved end of the year mark with one or two points), but we cannot confirm one hundred percent that this success is due only to this type of support they have received in school, during this school year. They have both been receiving support in their first or second language as well. To our knowledge, none of the two subjects has received any other form of pedagogical support outside school. At least not during this school year. But both students had been receiving support in school for a very long time before and until this school year they had received other forms of support outside school as well (different kinds of therapies). The students' maturity can also be an important factor in their evolution. Further investigation has to be done using this framework for support. A bigger number of students have to be involved in future studies and a more standardized method of evaluation of results has to be developed and implemented.

\section{CONCLUSIONS}

This framework might take some specialists from the field of psychology and educational science by surprise. "Since the beginning of this century, specialists aimed to eliminate from their experience all subjective reference. In this perspective, memory and intelligence for example are only what indicates the test that measures them. We reckon we are learning more about these mental functions when we are studying them from within." (De la Garanderie, 2013b, p. 21). We do have examples of successful educational systems, like the Finnish or Singapore systems, which operate by using a more personalized teaching, oriented towards students' individual learning needs (which could also be seen as personal to a specific student). This personalized concept could be easily defined and explained in antithesis with the standardized concept. Having standards is a positive thing. But standardizing the methods, the strategies a teacher or a student could use to get to those standards, admitting that there is only one way of doing things, seems as if we were annulling this concept that we call diversity, lately a widely, worldwide promoted concept.

The present is no longer in the industrial era where one's job is being reduced to doing repetitive actions and things, where the chief of station knew how things have to be done and things could be done only in one way. Today we live in the technological era, where people doing these repetitive actions are being replaced by machines and where people are being challenged to be creative, to think critically, to have the skills to work with 


\section{IULIA ȘCHIOPU}

all the available information which is just out there, people are asked to think in terms of problem-posing and be goal orientated people. All these demands do not really fall under the standardized concept. So we wonder, why does the vision of education still fall under this concept?

We find that youngsters should acquire knowledge that will enable them to develop skills like those mentioned above. Then, these skills will help them back, in acquiring new knowledge that youngsters need, and so on. This framework is one example that we believe it serves this purpose. Even though this framework could be seen as more appropriate in the context of special education, we believe it is worth trying outside the special education context. We believe it possible to extend this framework from a micro-system, like the special education context, to a macro-system, like a national education system.

\section{References}

Abbott, L. (2007). Northern Ireland Special Educational Needs Coordinators Creating Inclusive Environments: An Epic Struggle. European Journal of Special Needs Education, 22(4), 391-407.

Cole, B. A. (2005). Mission Impossible? Special Educational Needs, Inclusion and the Re-conceptualization of the Role of the SENCO in England and Wales. European Journal of Special Needs Education, 20(3), 287-307.

Cummings, D. K., Atkins, T., Allison, R., \& Cole, C. (2008). Response to Intervention. Investigating the New Role of Special Educators. Teaching Exceptional Children, 40(4), 24-31.

De Clercq, H. (2006). Autism from Within - A Handbook. Sweden: Intermedia Books.

De la Garenderie, A. (2013a). Le dialogue pédagogique avec l'élève. In A. de la Garenderie (ed.), Réussir ça s'apprend (pp. 581-694). Montrouge: Bayard.

De la Garenderie, A. (2013b). Les profils pédagogiques. In A. de la Garenderie (ed.), Réussir ça s'apprend (pp. 15-257). Montrouge: Bayard.

De la Garenderie, A. (2013c). Pédagogie des moyens d'apprendre. In A. de la Garenderie (ed.), Réussir ça s'apprend (pp. 259-382). Montrouge: Bayard.

Dulamă, M.E., \& Ilovan, O.-R. (2006). Developing Critical Thinking Using Specific Regional Geography Maps. Studia Universitas Babeş-Bolyai, Geographia, $L I(1), 137-146$.

Dulamă, M.E., \& Ilovan, O.-R. (2009). Study on Students' Critical Thinking Skills during Seminars of the Didactics of Geography. Acta Didactica Napocensia, 3(3), 19-30.

Dulamă, M.E., \& Ilovan, O.-R. (2015). Development of the Geography School Curriculum in Romania, from the $18^{\text {th }}$ Century to 1989. Transylvanian Review, XXIV(1), 255-284.

Freire, P. (2005). Education for Critical Consciousness. New York-London: Continuum International Publishing Group. 
Freire, P. (2011). Pedagogy of the Oppressed. New York-London: Continuum International Publishing Group.

Layton, L. (2005). Special Educational Needs Coordinators and Leadership: a Role too Far? Support for Learning, 20(2), 53-60.

Mackenzie, S. (2007). A Review of Recent Developments in the Role of the SENCo in the UK. British Journal of Special Education, 34(4), 212-218.

Policy on the Provision of Educational Support in the European Schools - 2012-05D-14-en-8. Retrieved 10 August 2016, from http://eursc.eu/getfile/1886/2

Provision of Educational Support in the European Schools - Procedural Document 2012-05-D-15-en-10. Retrieved 10 August 2016, from http: // eursc. eu/getfile/1887/2

Sahlberg, P. (2011). Finnish Lessons. What Can the World Learn from Educational Change in Finland? New York-London: Teachers College Press, Columbia University (electronic version of the book).

Schola Europaea (2007-2009). Official Site of the European Schools, Retrieved 10 August 2016, from www.eursc.eu

Shephard, D. (2008). NLP Practitioner Certification Training. The Performance Partnership.

Szwed, C. (2007). Reconsidering the Role of the Primary Special Educational Needs Co-ordinator: Policy, Practice and Future Priorities. British Journal of Special Education, 34(2), 96-104.

Takala, M., Pirttimaa, R., \& Törmänen, M. (2009). Inclusive Special Education: The Role of Special Education Teachers in Finland. British Journal of Special Education, 36(3), 162-172.

Wiliam, D. (2011). Embedded Formative Assessment. USA: Solution Tree Press (electronic version of the book).

Wiliam, D., \& Leahy, S. (2015). Embedding Formative Assessment: Practical Techniques for K-12 Classrooms. USA: Learning Science International (electronic version of the book). 